\title{
Converting Pirates through Participative Schemes for Digital Goods: Exploring "Pay What You Want" and Persuasive Computing in Online Music
}

\author{
Divinus Oppong-Tawiah \\ McGill University \\ divinus.oppong-tawiah@mail.mcgill.ca
}

\author{
Geneviève Bassellier \\ McGill University \\ genevieve.bassellier@mcgill.ca
}

\begin{abstract}
This study looks at how social factors can be leveraged to dissuade online piracy in digital This study leverage persuasive computing to influence consumers' decision making process regarding their acquisition of online music and seeks to identify how different persuasive techniques can, in a pay way you want context, anchor the consumers' reference price to an amount significantly different from 0.
\end{abstract}

\section{Introduction}

The ugly spectacle of online piracy in digital goods has received much attention but how social factors can be leveraged to support, influence and manipulate legal shopping while dissuading piracy is not well understood. Digitized information goods such as music, books and movies are highly susceptible to piracy [1] because they can be copied at zero marginal costs [2] as creation and distribution technologies continues to advance ahead of existing strategies for their packaging, pricing and sale, especially with small-sized music files [3]. Thus, music providers are particularly challenged as they strive to be profitable in a digital economy where consumers can obtain music for free. Some early estimates suggested a decline in music sales from $\$ 13.7$ billion in 1998 to $\$ 8.5$ billion in 2008 (Recording Industry Association of America [4]), and industry players have been unequivocal in blaming this trend on online piracy. In addition, copyright protection technologies such as Digital Rights Management systems have been ineffective at combatting online piracy [5], and music content providers are being forced to rethink their digital business strategies [6].

Consequently, music producers are reacting by delegating more pricing power to consumers through participating pricing schemes such as "Pay What You Want (PWYW)" and "Name Your Own Price (NYOM)" [7] in attempt to convert sales from "free" consumers. Such pricing schemes are only just emerging and their advantages over traditional fixed prices are yet to be established. The few studies conducted to date have reported that consumers pay positive amounts for music under PWYW due to prosocial behaviors (e.g. [8]; [9]) although the amounts paid were unprofitable. More broadly, we are still limited in our understanding of what allows individuals to break from social and legal constraints to pirate digital music, and how participative pricing mechanisms can be effectively leveraged to persuade consumers to pay for online music.

The current study explores the welfare of music producers relying on PWYW pricing schemes to sustain profits. Such producers face the risk that consumers may exploit their control of prices and pay nothing at all or a price below the seller's costs [10]. Additional persuasion may therefore be necessary to influence prices paid, but what and how persuasive techniques influence potential shoppers to yield desirable outcomes is unclear. Thus, we address this related question: How can consumers purchasing music in a PWYW scheme be persuaded to pay an amount different from $\$ 0$ ? This question is important because it can potentially build on extant PWYW research to expand understanding of how consumers who have access to free online music can be converted to pay through legal channels.

In the rest of the paper, we first briefly outline relevant literatures in participative pricing schemes and persuasive computing, and develop a research model to address our question. We then describe our on-going methodology for collecting data to empirically test the model. We conclude by discussing expected results and their anticipated theoretical and practical implications.

\section{Theoretical Background}

\subsection{Participative Pricing Schemes and Pay What You Want}

Pricing strategies generally aim to maximize sellers' profits by capturing consumers' heterogeneous product valuations and accounting for competition and cannibalization. This is because consumers' reactions 
to different prices may not be purely rational but driven by behavioral aspects such as perceptions and preferences [10]. Therefore, sellers are exploring innovative and unconventional pricing strategies such as auctions, Name-Your Own-Price, and Pay-WhatYou-Want, that seek to involve consumers in the pricesetting process ([7]; [32]; [33]; [34]; [35]). The enabling role of the internet in providing a direct link to consumers has made it easier to implement participative pricing mechanisms [36]. Such mechanisms allow for differentiated prices and accounts for heterogeneous valuations of consumers to increase efficiency [37], while also enabling sellers to serve buyers who would otherwise be priced out of the market [2]. Participative pricing mechanisms have been shown to be effective and preferable for consumers. For example, consumers preferred to participate actively in setting the final price than to accept posted prices, and the higher perceived control of the buyers led to a greater intent to purchase [38]. In addition, consumers have higher fairness perceptions and satisfaction when they play a role in the pricesetting process than when the prices are set by the retailer [39]. Sellers implementing participative pricing model may also attract consumers' attention, potentially leading to (new) customers as their popularity increases by word-of-mouth [10].

PWYW is the participative pricing model of interest in this study. It is different from other participative pricing models because buyers are given absolute control over the price-setting so that the buyer can set any price above or equal to zero which the seller cannot reject [10]. We focus on PWYW because it has been successfully implemented for online music (Radiohead's In Rainbows album Oct to Dec 2007 who reported unprecedented profits) and gaining increased attention in online music research (cf. [8]; [9]). However, there is the risk that buyers exploit their control and pay nothing at all or a price well below seller's cost [10]. Such a scenario will have several adverse implications for an online music provider implementing a PWYW model. Firstly, no minimum price is implemented that could protect the music provider against payment of $\$ 0$. Secondly, under PWYW, the music provider supplies a legitimate channel for distribution to pirates. Therefore, the provider relinquishes any statutory protection they would otherwise enjoy under copyright laws. In effect, PWYW may provide an opportunity for pirates to legalize their activities while potentially denying the music provider the legal means for cost recovery or compensations for copyright infringement. Therefore, given the uncertainty of buyer's pricing behavior in PWYW and the impact of PWYW on sellers' revenues, it is important to explore additional persuasive mechanisms that can balance the scale in the music providers' favor by encouraging buyers to be willing to pay an amount sufficiently different from $\$ 0$.

\subsection{Persuasive Computing}

Persuasive computing (the use of computers as persuasive technologies) can be a useful mechanism for increasing consumer willingness-to-pay for online music under a PWYW pricing model. Persuasive computing is a relatively new paradigm in humancomputer interaction (HCI) research that focuses on the use of computers to persuade behavioral change in users [40]. Persuasive computing draws on the Computer As a Social Actor (CASA) model [41] and the Media Equation theory [42] which both posit that individuals respond to and interact with media and technology just as they would in a social interaction with other individuals.

Persuasive computing has been applied to study and encourage behavior change in a number of domains, notably health care and environmental sustainability. A survey of the literature shows that the targeted behaviors are often those that are entrenched and not easily amenable to change (e.g. smoking, dieting and physical activity in health care; energy and water use, air pollution, recycling and waste disposal in sustainability) [46]. Thus, persuasive designs present interventions for encouraging change in individuals toward desired behaviors when, left on their own, such individuals may not be aware of the need for change or may simply be comfortable with the status quo. We argue that in the context of this study, the behavior of individuals who consume online music for free can be described as behaviors that require specific interventions before change can happen. That is, ceteris paribus, "free" consumers will continue to perpetuate that behavior unless deliberate effort is expended to counter this behavior.

At the core of persuasive designs is the notion that feedback on behavioral performance framed in a positive or negative way can guide individuals to make changes to favor the desired behavior or attitude [47]. When considering online piracy as a crime, one social theory from criminology that can be combined with feedback to change behavior is the theory of Neutralization Techniques [48]. Neutralization techniques theory posits that individuals' intentionally suspend their moral and conscientious compass temporary to commit an illegitimate act. That is, individuals learn techniques they can use to rationalize their actions and excuse themselves from personal responsibility for the time being in order to commit a crime [48]. Five types of justifications commonly used to neutralize demands for social conformity include: 
denial of responsibility ("it is not my fault'), denial of injury ("no harm will result from my actions",), denial of victim ("'nobody got hurt"), condemnation of the condemners ("how dare they judge me, considering how corrupt and hypocritical they themselves are"), and appeal to higher loyalties ("there is a greater and higher cause'") [48]. (See first column in Table 1).

Neutralization techniques are best applicable to minor types of crimes and delinquency [49] which supports the theory's applicability to music piracy [24]. Studies that have examined the use of neutralization techniques in digital piracy found a significant but weak link with software piracy ([50]; [51]), moderate levels of music piracy [24], and diminishing longitudinal effects in quasi-experimental field settings [29]. However, while prior studies focused on the types and levels of neutralization at work in online music piracy, the present study draws on their findings to pursue a uniquely different goal; to develop and implement persuasive techniques aimed at countering the effect of neutralization techniques used by "free" online music consumers.

\section{Research Model}

The research model for this study is shown in Figure 1. In the sections below, we develop hypotheses about consumer willingness-to-pay in PWYW contexts under persuasive intervention.

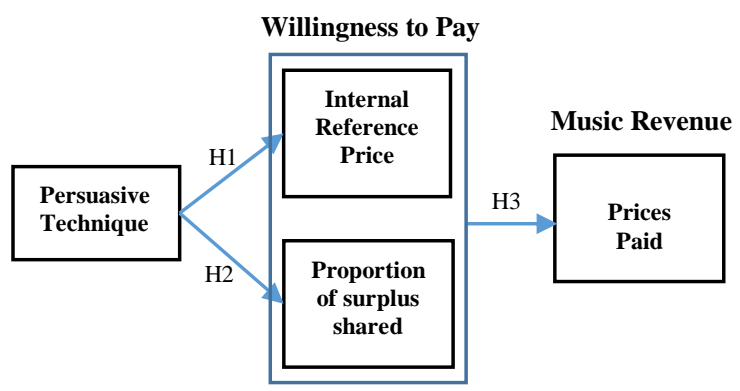

Figure 1. Consumer WTP under Persuasion in PWYW Pricing for Online Music

\subsection{Willingness-to-Pay for Online Music under PWYW}

In a PWYW setting where consumers can determine any price for the product they buy, the final prices paid consists of two principal components: the buyers' internal reference price (their valuation of the normal cost of the product) and the proportion of the reference price that the buyer is willing to discharge to the seller (Kim et al, 2009). The marketing literature suggests that reference prices have a strong impact on consumer behavior [52]; [53]. Consumers' perceptions of current prices are influenced by their internal reference prices based on past prices or on externally provided prices such as advertised prices or prices of competing products [54]. This argument is related to the notion of constructed preferences [68] which suggests that consumers are often uncertain about their valuation of a product and use cues to determine their willingness to pay (WTP). While such cues can be consumers' internal reference price or an externally provided reference price, PWYW products often offer no external reference prices for products traded and consumers have to rely solely on their internal reference prices [10].

Online pirates have been shown to deny responsibility for their actions on the basis that it is not financially possible to legally purchase all the music they desire [24]. Yet, consumers who frequently access online music for free may not even be aware of market prices of full albums or individual track downloads. Therefore, when a legitimate channel is made available under PWYW, denial of responsibility for payment by "free" consumers may arise from the ambiguity of prices they think they are expected to pay, irrespective of their valuation of the music. This allows them to contend that if an anchor price for downloading music were clearer, then they would resort to setting a reasonable price for the music. Therefore, this neutralization technique on the part of the consumer can be directly countered with a persuasive intervention designed to present external reference prices for consumers (e.g compare prices on iTunes, etc.) while in the process of purchasing music under PWYW. Empirically, Regner and Barria [9] found that the recommended payment of $\$ 8$ for an album was actually paid $55 \%$ of the time, although their voluntary pricing scheme was not a true PWYW because it required a $\$ 5$ minimum payment which was paid by $14 \%$ of the consumers. Therefore, in PWYW context, a persuasive intervention that provides an external reference price will serve as an additional cue to aid the construction of a consumer's internal reference price in the direction of an economically acceptable price range. The first hypothesis is thus:

H1: Implementation of persuasive techniques in a PWYW platform will increase internal reference price valuation by consumers of online music

In addition, a PWYW setting that gives absolute control of price determination to a buyer should lead a rational customers who wishes to maximize her single purchase utility to exploit the mechanism to pay a price of zero [10]. However, this is often not the case because the exchange between the buyer and seller is governed more by social-market than money market relationships [57]. That is, in money-market 
relationships, exchange between two parties is regulated by the use of a value or a utility metric, e.g., the price for a product [58] but non-posted prices or non-payments lead exchange partners to act according to social exchange norms (i.e., norms of reciprocity, norms of cooperation or norms of distribution) [59] which in turn influence the buyer's behavior [57]. Since PWYW dissolves the usual money-market relationship between seller and buyer, the use of social exchange norms such as impression management (not willing to appear cheap) and avoiding social disapproval should lead individuals to pay prices greater than zero at PWYW in face-to-face interactions [10]. Empirically, field studies on consumers' WTP under PWYW find that consumers often pay positive amounts due to pro-social behaviors ([58]; [59]; [8]; [9]).

Pro-social behaviors arising from online social influence has been shown to influence consumer decisions such as what music to subscribe for [60] or listen to [61], what books to purchase [62], what videos to watch on youtube [63], and how much contribution to make in crowdfunding [64]. Given the strong impact of social influence on online consumer behavior, prosocial persuasive techniques that operationalize measures to counter neutralization techniques used by "free" consumers are likely to effectively motivate them to share a higher proportion of their surplus with the music provider. That is, individuals who consume free online music are known to employ neutralization techniques such as denial of responsibility (when individuals note the widespread availability of unauthorized music online or the ambiguity of laws regulating downloading); denial of injury/denial of victim (when individuals feel that the recording industry reaps a sizable profit and has enough capital not to suffer lost revenue from free downloads); condemnation of condemners (when individuals fault the music industry for "overcharging', the consumer through monopolistic practices); and appeal to higher loyalties (when individuals contend that obtaining the unauthorized music fulfills a greater cause or purpose, such as meeting the needs of significant others or a work or school obligation) ([30]; [24]).

In a PWYW setting, these rationalizations will negatively influence the proportion of surplus consumers will be willing to share with the music provider. Yet, because such rationalizations are very personal, they may not sufficiently manifest themselves in social norms to be influenced by social media interventions alone. Personal rationalizations can be challenged by presenting persuasive arguments framed to respond directly to the neutralization techniques used by free music consumers. Such persuasive techniques designed to expose illegitimate justifications for errant behavior can cause consumers to revise their attitudes, assumptions and beliefs held about free online music and likely increase the proportion of surplus they will share with PWYW music providers. Personal rationalizations can be further weakened by additional persuasive techniques such as providing a simulating experience for consumers to directly link their payments to a music provider's increased wealth, providing tailored feedback to reinforce positive payments, timing persuasive messages to appear at an opportune time (kairos effect) ([43]; [44]), and using seductive design techniques such as aesthetics, humor, curiosity, surprise and delighters [45] to elicit positive user emotions while they are engaged on the PWYW platform. Given that persuasive techniques can neutralize the rationalizations employed by free consumers in PWYW and encourage them to perform more pro-social behaviors, the second hypothesis is thus:

H2: Implementation of persuasive techniques in a PWYW platform will increase the proportion of surplus shared by consumers of online music

\subsection{WTP and Music Revenues in PWYW under Persuasion}

We propose that under persuasion, the level of revenue realized will be influenced by persuasive techniques through their effects on internal reference price and proportion of surplus shared. Hypothesis 1 and 2 suggest that persuasive techniques designed to attenuate the use of neutralization techniques by PWYW music consumers will increase their internal reference price valuation for music and the proportion of surplus they might be willing to share. If these manipulations are successful, the final prices paid for music will be higher than in PWYW contexts with no persuasions. Yet, neutralization theory would suggest a more nuanced effect of the drivers of internal reference price and proportion of surplus shared by consumers on the final prices paid. That is, research on neutralization theory proposes that the relationship between neutralizations and deviance may be curvilinear ([65]; [49]) because individuals who rely most on neutralizations to excuse their behavior are those who are only partly committed to the behavior under study. In other words, neutralization techniques may not be relevant for those individuals who are either totally committed to conventional behaviors or totally committed to deviant behaviors [65].

The nonlinear effect of neutralization techniques has been found significant cross-sectionally across different levels of student participation in music piracy 
(Ingram and Hinduja, 2008) and longitudinally across earlier versus later levels of music piracy over a fourweek study [30]. Drawing on these findings, persuasive interventions designed to counter neutralization techniques may also result in nonlinear effects on WTP and revenues realized from music consumers in PWYW. Specifically, consumers may initially respond to moderate levels of persuasive techniques by upwardly adjusting their internal reference prices and proportion of surplus they want to share until the level of their perceived control (e.g. ability to pay for music based on their income) [25]. However, stronger persuasive techniques (e.g. providing a "too high" external reference price cue) will lead consumers to believe they have little control over their WTP. Consequently, they may choose not to make any purchase on the PWYW platform because they are no longer able to rely on neutralization techniques to suppress their guilty feeling about their inability to pay for the music. Thus, consumers may experience a form of disutility whereby marginal increment in persuasive techniques beyond their perceived control over their WTP causes them to altogether abandon the music sold through PWYW. The likely effect on revenue is that higher prices will be paid for lower or higher volume of downloads (depending on song popularity) until consumers perceive a lack of control over their WTP, resulting in low volume of downloads. Formally, these arguments are stated in the following hypotheses:

H3a: High internal reference price and proportion of surplus shared by consumers under a moderate level of persuasion in PWYW will lead to high prices paid

$\mathrm{H} 3 \mathrm{~b}$ :High internal reference price and proportion of surplus shared, induced via a higher level of persuasion in PWYW will lead to nonpayment

\section{Methods}

\subsection{Experimental Design}

We have selected to test our model by developing a persuasive system to conduct a lab experiment, an approach that is consistent with recent studies in behavioral economics. In our experimental set up, the unit of analysis is a song offered through the context of PWYW. We will implement a $3 \times 4$ factorial design in which we use 3 levels of persuasion (control, moderate, and high) to manipulate four types of persuasive techniques (techniques that counter denial of responsibility, denial of injury/victim, condemnation of condemners, and appeal to higher loyalties). The dependent variable is the price paid for music by participants.

\subsection{Operationalization}

The PWYW context is being operationalized as an online website that hosts songs for participants to sample and purchase. Song profiles are differentiated by quality using chart rankings and all participants have access to the same song list. Participants are asked to browse all songs and determine the price they would pay for each song (i.e. their internal reference price). Participants then have the option of purchasing the songs they like by making an offer (i.e. the actual price paid) and downloading their chosen songs. To avoid anchoring effects between their internal reference price and the actual prices paid, each song is matched with a similarly ranked song and participants determine prices for the first list of songs (list A) but make purchases in the matched list of songs (list B). In effect, participants' reference prices for songs on list A will be matched to their purchase prices for similarly ranked songs on list B.

Persuasive techniques is operationalized as additional features on the PWYW website. The control condition will have no persuasive elements and participants will have access to only the basic features of the PWYW context. The treatment conditions will have persuasive elements embedded in the PWYW context. These elements aim to provide feedback to participants on the impact of their performance (willingness to pay) while also generally eliciting positive emotional excitation to encourage them to be more willing to pay for songs.

The levels of persuasion will be operationalized with persuasive messages framed to counter the neutralization techniques used by "free" music consumers. Our persuasive techniques counter four types of neutralization techniques used by free music consumers and are largely adapted from instruments used by Hinduja [51] and Ingram and Hinduja [24]. For the levels of persuasion, the control condition will get no messages for any type of persuasive technique. The moderate condition (moderate persuasion) provides mild persuasive messages designed to counter claims of denial of responsibility, denial of injury/victim, condemnation of condemners, and appeal to higher authority in order to encourage participants to understand the need to pay for music and act accordingly. The high condition (high persuasion) provides stronger persuasive messages designed to counter neutralization techniques but make participants feel the demands made of them are too high even though they understand the need to pay for music. 


\subsection{Data Collection}

Data is collected through a web-based experimental survey. In the first phase, we are targeting undergraduate university students. We intend to complement this data with additional data from Mechanical Turkers in phase 2. Although there are concerns with student samples for generalizing to the broader population, its use in the current study is appropriate because it has been reported that young people are the most likely to obtain their music for free [11] and university environments have been described as hotbeds for free downloading of digital songs [4]. Our $3 \times 4$ factorial design has 12 cells in total and we calculate that at conventional alpha, a sample size of 240 (20 per cell between-group) will yield adequate power to detect a medium effect size. Participants will be randomly assigned to a cell. The data collected from students include reference prices for songs on list A, paid prices for matched songs on list B, and the number of downloads for songs on list B. Additionally, students will provide responses to demographic questionnaires. Students who agree to participate are provided a link to one of the PWYW context websites where they read introduction to the tasks to be performed and sign consent forms. A pre-test is being conducted with a small set of students to assess and improve the psychometric properties of manipulations before the main data collection.

\subsection{Manipulation Checks}

On completion of the experiment, all participants will be asked to complete an exit questionnaire which asks whether their reference prices determined for songs on list A influenced their actual payments for songs downloaded on list B. In addition, participants in the persuasive conditions will be asked whether they found (counter-neutralization) persuasive messages reasonable or outrageous. Participants in the high persuasion condition will be asked to indicate whether messages made them feel guilty and yet perceive a lack of control over their ability to pay.

\section{Discussion and Conclusion}

Our on-going study aims to understand the welfare of music providers who rely on PWYW pricing schemes to sustain their profitability in a digital environment that fosters free consumption of their products. We have proposed a model to explain how consumers purchasing music in a PWYW scheme can be persuaded to pay amounts significantly different from $\$ 0$. Using theories of neutralization and persuasive computing design principles, the proposed model suggests that persuasive techniques framed around messages that counter the rationalizations individuals use to consume music for free can encourage them to change their behavior and pay for online music. The study aims to test this model through an online survey-based lab experiment.

However, although experiments offer a high degree of control, we recognize in advance the threat to internal validity that can arise from halo effects between asking participants to state a reference price and then asking them to purchase a song. That is, participants' willingness to pay may be confounded by the experimental manipulation. To address this problem, the study proposes to use a matched pair of songs in order to match reference price stated for one song to the price paid for the counterpart song. Yet, the selection and matching of songs warrants additional caution.

The results expected from the study will have some important implications for management of digital music production and distribution and research on pricing models for digital goods. For managers of digital music, recent progress in digital music distribution through legal retailers such as iTunes and streaming services such as Spotify have not discouraged music piracy through illegal peer-to-peer (P2P) file-sharing networks, cyberlockers and aggregators, unlicensed streaming and stream ripping services. Lost revenues from piracy continue to dwarf realized revenues from digital music sales, and the quest for more effective pricing schemes that can convert more pirates to pay for music is still necessary. The current study can potentially make a contribution in this area. If persuasive techniques can mitigate the risks involved in PWYW pricing schemes, music providers will have an additional pricing strategy for targeting a segment of the pirates who rely on neutralization techniques to justify their behavior. For research, results from the proposed study can contribute an understanding of persuasive techniques as a more effective mechanism for eliciting pro-social behaviors to study and manipulate their impact on consumer behavior in online digital goods and services marketed through social influence. In this regard, our study potentially contributes to growing calls by information systems scholars (e.g. [6]; [67]) to consider the role of social factors in the digital business strategies of content providers.

\section{References}

[1] Clemons, E.K., and Lang, K.R. 2003. "The Decoupling of Value Creation from Revenue: A Strategic Analysis of the Markets for Pure Information Goods. Information Technology and Management. 4(2): 259-287. 
[2] Bakos, Y. 1998. "The Emerging Role of Electronic Marketplaces on the Internet." Communications of the ACM 41(8): 35-42.

[3] Bhattacharjee, S., Gopal, R. D., and Sanders, G. L. 2003. "Digital Music and Online Sharing: Software Piracy 2.0?', Communications of the ACM (CACM) 46(7):107-111.

[4] RIAA 2009. 2008 Year-End Shipment Statistics [http://www.riaa.com/keystatistics.php].

[5] Sinha, R., Machado, F., and Sellman, C. 2010. "Don't Think Twice, It's All Right: Music Piracy and Pricing in a DRM-free Environment." Journal of Marketing, 74: 40-54.

[6] Oestreicher-Singer, G., and Zalmanson, L. 2013. "Content or Community? A Digital Business Strategy for Content Providers in the Social Age." MIS Quarterly 37(2), 591-616.

[7] Krämer, F., Schmidt, K. M., Spann, M., and Stich, L. 2015. Delegating Pricing Power to Customers: Pay What You Want or Name Your Own Price (May 2015). CEPR Discussion Paper No. DP10605. Available at SSRN: http://ssrn.com/abstract=2608063

[8] Ramaprasad, J., Desmeules, R., and Bassellier, G. (2012). Can Social Come to the Rescue? Monetizing Music in the World of Free. Working Paper.

[9] Regner, T., Barria, J.A. 2009. Do consumers pay voluntarily? The case of online music. Journal of Economic Behavior \&Organization. 71(2) 395-406.

[10] Kim, J-Y., M. Natter, M. Spann. 2009. Pay what you want: A new participative pricing mechanism. Journal of Marketing 73: 44-58.

[11] International Federation of Phonographic Industries (IFPI). 2006. The Recording Industry 2006 Piracy Report: Protecting Creativity in Music.

[12] International Federation of Phonographic Industries (IFPI) 2008. Digital Music Report 2008.

[13] International Federation of Phonographic Industries (IFPI) 2014. Digital Music Report 2014: Lighting Up New Markets.

[14] Michel, N.J. 2006. "The Impact of Digital File Sharing on the Music Industry: An Empirical Analysis." Topics in Economic Analysis and Policy. 6(1): 1-22.

[15] Peitz, M. and Waelbroeck, P. 2004. "The Effect of Internet Piracy on Music Sales: Cross-Section Evidence." Review of Economic Research on Copyright Issues 1(2): 7179

[16] Rob, R. and Waldfogel, J. 2006. "Piracy on the High C's: Music Downloading, Sales Displacement, and Social Welfare in a Sample of College Students." Journal of Law and Economics 49(1): 29-62.

[17] Oberholzer-Gee, F. and Strumpf, K. 2007. "The Effect of File Sharing on Record Sales: An Empirical Analysis." Journal of Political Economy 115(1): 1-42.

[18] Koh, B., Murthi, B. P. S., and Raghunathan, S. 2014. "Shifting Demand: Online Music Piracy, Physical Music Sales, and Digital Music Sales." Journal of Organizational Computing and Electronic Commerce 24(4): 366-387.

[19] Banerjee, D., T. P. Cronan, and T. W. Jones. 1998. "Modeling IT Ethics: A Study in Situational Ethics.' MIS Quarterly 22(1): 31-60.
[20] Cesareo L., and Pastore, A. 2014. "Consumers' Attitude and Behavior Towards Online Music Piracy and Subscription-Based Services." Journal of Consumer Marketing 31(6/7): 515 - 525.

[21] D'Astous, A., Colbert, F., and Montpetit, D. 2005. "Music Piracy on the Web - How Effective are Anti-Piracy Arguments? Evidence from the Theory of Planned Behavior.' Journal of Consumer Policy 28: 289-310.

[22] Gopal, R. D., Sanders, G. L., Bhattacharjee, S., Agrawal, M., and Wagner. S. 2004. "A Behavioral Model of Digital Music Piracy." Journal of Organizational Computing and Electronic Commerce 14: 89-105.

[23] Hinduja, S. 2006. Music Piracy and Crime Theory. New York: LFB Scholarly Inc.

[24] Ingram, J., and Hinduja, S. 2008. "Neutralizing Music Piracy: An Empirical Examination.” Deviant Behavior 29(4): 334-366.

[25] Morton, N., and Koufteros. X. 2008. "Intention to Commit Online Music Piracy and its Antecedents: An Empirical Investigation." Structural Equation Modeling 15: 491-512.

[26] Zentner, A. 2005. "File Sharing and International Sales of Copyrighted Music: An Empirical Analysis with a Panel of Countries." Topics in Economic Analysis \& Policy. 5(1): $1-15$.

[27] Sudler, H. 2013. "Effectiveness of anti-piracy technology: Finding appropriate solutions for evolving online piracy." Business Horizons, 56(2), 149-157.

[28] Chiou, J. S., Huang, C., and Lee. H. 2005. "The Antecedents of Music Piracy: Attitudes and Intentions." Journal of Business Ethics 57(2):161-174.

[29] Higgins, G. E. 2007. "Digital piracy: An examination of Low Self-Control and Motivation using Short-Term Longitudinal Data. CyberPsychology and Behavior 10: 523529.

[30] Higgins, G. E., Wolfe, S. E, and Marcum, C. D. 2008. "Music Piracy and Neutralization." International Journal of Cyber Criminology 2(2): 324-336.

[31] Elberse, A., and Bergsman. J. 2008. Radiohead: Music at Your Own Price (B). Harvard Business School Supplement 508-111, May 2008. (Revised June 2009.) Harvard Business School Boston, MA.

[32] Johnson, J. W., and Cui, A. P. 2013. "To influence or not to influence: External reference price strategies in paywhat-you-want pricing." Journal of Business Research, 66(2), 275-281.

[33] Weisstein, F. L., Kukar-Kinney, M., and Monroe, K. B. 2016. "Determinants of consumers' response to pay-whatyou-want pricing strategy on the Internet." In Press, Journal of Business Research.

[34] Schröder, M., Lüer, A., and Sadrieh, A. 2015. "Paywhat-you-want or mark-off-your-own-price-A framing effect in customer-selected pricing." Journal of Behavioral and Experimental Economics, 57, 200-204.

[35] Roy, R., Rabbanee, F. K., and Sharma, P. 2016. "Antecedents, outcomes, and mediating role of internal reference prices in pay-what-you-want (PWYW) pricing." Marketing Intelligence \& Planning, 34(1), 117 136. 
[36] Kannan, P. K. and Kopalle, P. K. 2001. "Dynamic Pricing on the Internet: Importance and Implications for Consumer Behavior." International Journal of Electronic Commerce, 5(3): 63-83.

[37] Spann, M., and Tellis. G. J. 2006. "Does the Internet Promote Better Consumer Decisions? The Case of NameYour-Own-Price Auctions. Journal of Marketing 70(1): 6578.

[38] Chandran, S., and Morwitz, V. G.. 2005. "Effects of Participative Pricing on Consumers' Cognitions and Actions: A Goal Theoretic Perspective." Journal of Consumer Research 32(2) :249-259.

[39] Haws, K. L., and Bearden, W. O. 2006. "Dynamic Pricing and Consumer Fairness Perceptions." Journal of Consumer Research, 33(3): 304-11.

[40] Fogg, B. J. 1998. "Persuasive Computers: Perspectives and Research Directions." Proceedings of the 1998 ACM Annual Conference on Human Factors in Computing Systems:18-23.

[41] Nass, C., Moon, Y., Fogg, B. J., Reeves, B. and Dryer, D. C. 1995. "Can computer personalities be human personalities?" International Journal of Human-Computer Studies 43: 223-239.

[42] Reeves, B., and Nass, C. 1996. The media equation: How people treat computers, television, and new media like real people and places. Cambridge, UK: Cambridge University Press.

[43] Fogg, B. J. 2003. Persuasive Technology: Using Computers to Change What We Think and Do, , San Francisco, CA: Morgan Kaufman Publishers.

[44] Oinas-Kukkonen, H. and Harjumaa, M. 2009. "Persuasive systems design: key issues, process model, and system features", Communications of the Association for Information Systems 24: 485-500.

[45] Anderson, S. P. 2011. Seductive Interaction Design: Creating Playful, Fun, and Effective User Experiences. Berkeley, CA: New Riders Publishing.

[46] Ferebee, S. S. 2010. "Successful Persuasive Technology for Behavior Reduction: Mapping to Fogg's Gray Behavior Grid." Proceedings of the 5th International Conference on Persuasive Technologies: 70-81.

[47] Tversky, A. and Kahneman, D (1981). "The Framing of Decisions and the Psychology of Choice." Science 211 (4481): 453-458.

[48] Sykes, G. and Matza, D. 1957. "Techniques of Neutralization: A Theory of Delinquency.' American Sociological Review 22(6): 664-670.

[49] Maruna, S. and Copes. H. 2005. "What Have We Learned in Five Decades of Neutralization Research?' Crime and Justice: A Review of Research 20: 221-320.

[50] Goode, S., and Cruise, S. (2006). What motivates software crackers? Journal of Business Ethics 65: 173-201.

[51] Hinduja, S. 2007. "Neutralization Theory and Online Software Piracy: An Empirical Analysis." Ethics and Information Technology 9(3): 187-204.

[52] Mayhew, G. E., and Winer, R. S. 1992. "An Empirical Analysis of Internal and External Reference Prices Using Scanner Data." Journal of Consumer Research 19 (1): 62-70.
[53] Rajendran, K. N. and Tellis, G. J. 1994. "Contextual and Temporal Components of Reference Price." Journal of Marketing 58(1): 22-34.

[54] Grewal, D., Monroe, K. B., and Krishnan, R. 1998. "The Effects of Price-Comparison Advertising on Buyers' Perceptions of Acquisition Value, Transaction Value, and Behavioral Intentions.” Journal of Marketing 62(2): 46-59.

[55] Osterhus, T. L. 1997. "Pro-Social Consumer Influence Strategies: When And How Do They Work." Journal of Marketing 61(4): 16-29.

[56] Heyman, J., and Ariely, D. 2004. "Effort for Payment: A Tale of Two Markets." Psychological Science 15(11): 78793.

[57] Shampanier, K., Mazar, N., and Ariely, D. 2007. "Zero as a Special Price: The True Value of Free Products." Marketing Science 26(6): 742-57.

[58] Gautier, P. A., van der Klaauw, B. 2012. Selection in a field experiment with voluntary participation. Journal of Applied Econometrics. 27(1) 63-84.

[59] Gneezy, A., Gneezy, U., Nelson, L.D., Brown., A. 2010. Shared social responsibility: A field experiment in paywhat-you-want pricing and charitable giving. Science. 329 : 325-327.

[60] Bapna, R., and Umyarov, A. 2011. "Are Paid Subscriptions on Music Social Networks Contagious? A Randomized Field Experiment. Working Paper

[61] Dewan, S., and Ramaprasad. J. 2012. "Music Blogging, Online Sampling, and the Long Tail" Information Systems Research 23(3): 1056-1067.

[62] Chevalier, J.A., and Mayzlin, D. 2006. "The Effect of Word of Mouth on Sales: Online Book Reviews. Journal of Marketing. 43(3): 345-354.

[63] Susarla, A., Oh, J.-H., and Tan, Y. 2012. "Social Networks and the Diffusion of User-Generated Content: Evidence from YouTube." Information Systems Research, 23(1): 23-41

[64] Burtch, G., Ghose, A., and Wattal, S. 2013. "An Empirical Examination of the Antecedents and Consequences of Contribution Patterns in Crowd-Funded Markets." Information Systems Research, 24(3): 499-519.

[65] Copes, H., and Williams, J. P. 2007. "Techniques of Affirmation: Deviant Behavior, Moral Commitment, and Subcultural Identity." Deviant Behavior 28: 247-272.

[66] RIAA 2014. Institute of Policy Innovation [www.ipi.org. 2014]

[67] Berger, B., Matt, C., Steininger, D. M., and Hess, T. 2015. It Is Not Just About Competition with "Free": Differences Between Content Formats in Consumer Preferences and Willingness to Pay. Journal of Management Information Systems, 32(3), 105-128.

[68] Bettman, J. R., Luce, M. F., and Payne, J. W. 1998. "Constructive Consumer Choice Processes." Journal of Consumer Research 25(3): 187-217. 


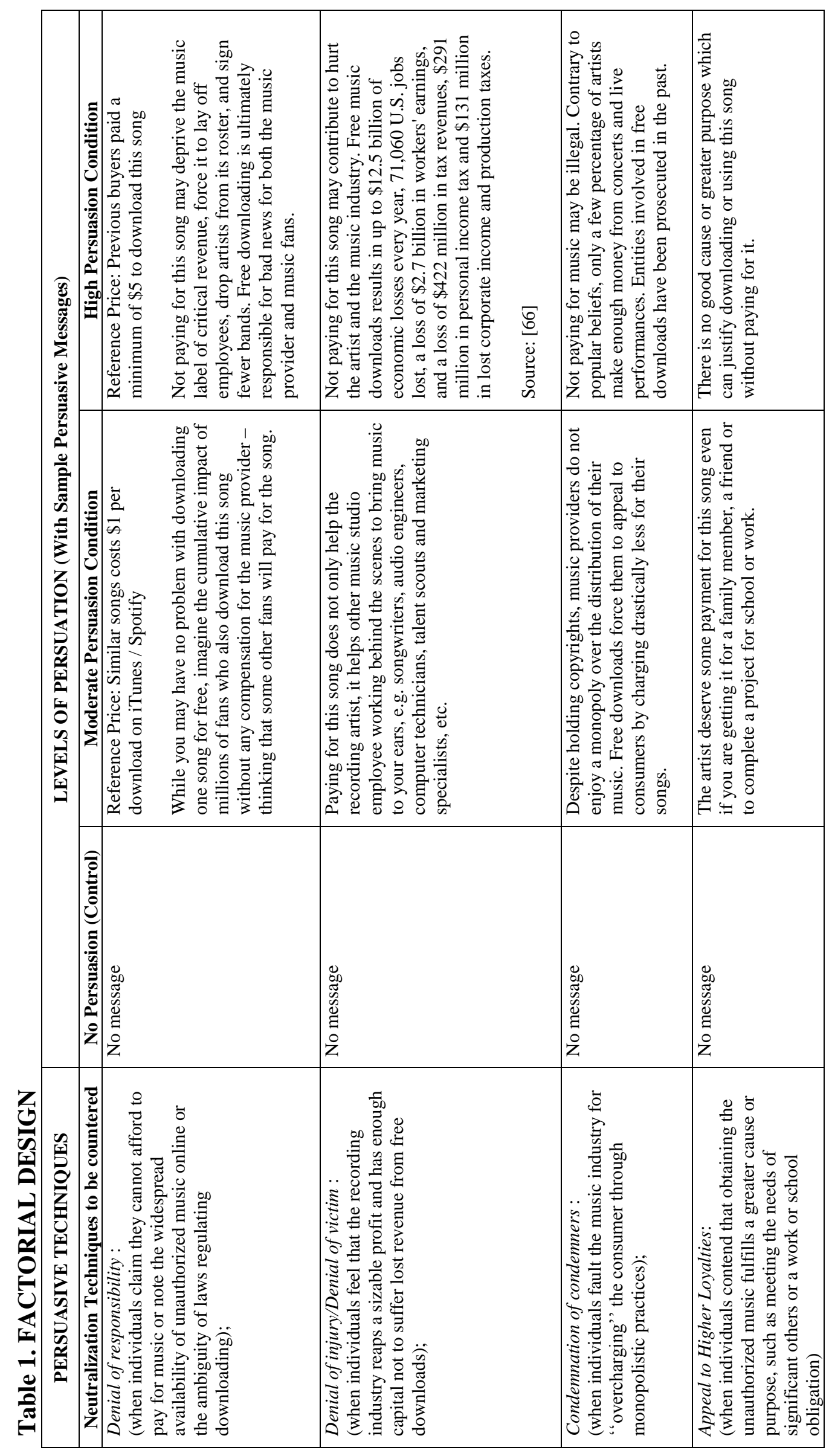

